\section{WATCHING NEURONS \\ HAND OFF MOLECULES}

Stephen W. Carmichael, ${ }^{1}$ Mayo Clinic

carmichael.stephen@mayo.edu

Since the discovery of nerve growth factor, it has been thought that neurotrophic factors are released or secreted from target cells. However, more recently it has been suggested that a specific neurotrophic factor known as brain-derived neurotrophic factor (BDNF) may reach target cells directly from presynaptic axons. It has not been known how these molecules get from the neuron in which they are produced to the target cells. Keigo Kohara, Akihiko Kitamura, Mieko Morishima, and Tadaharu Tsumoto ${ }^{2}$ have demonstrated that BDNF is transported anterogradely from presynaptic neurons to target neurons.

It would be technically difficult, if not impossible, to demonstrate transsynaptic transport in cortical neurons in situ. Kohara et al. got around this problem by using cultured cortical neurons extracted from the cortex of neonatal mice. A plasmid that contained the complimentary DNA for BDNF and green fluorescent protein (GFP) was injected directly into the nuclei of selected neurons under direct vision using a 40x objective on an inverted microscope. Green fluorescence was observed within these neurons within 24 hours, indicating that the BDNF-GFP molecule was adequately transcribed and translated within the neurons. The fluorescent pattern was seen as points of fluorescence grouped as clusters within nerve processes, whereas in the nerve cell bodies the fluorescent signal was dense and diffused. This pattern of fluorescence was quite similar to that previously reported for endogenous BDNF. To further confirm that the fluorescent signal corresponded to BDNF in the plasmidinjected neurons, some neurons were fixed and stained immnunocytochemically with an antibody to BDNF. Comparing the micrographs of the fluorescing cells to the pattern of BDNF localized immnunocytochemically was almost identical within the same celi, as confirmed by superimposition of micrographs. There were a small number of points seen within the distal aspect of nerve cell processes that did not correspond to fluorescent points and these were interrupted to be endogenous BDNF. The plasmid-injected neurons were shown to be electrophysiologically the same as non-injected neurons.

The next challenge for Kohara et al. was to determine if fluorescence-tagged BDNF was localized within axons of the injected cells. To separate dendrites from axons, they used two approaches. One was to immnunocytochemically detect microtubule associated protein 2 (MAP2) which is known to exist in dendrites but not axons. Other neurons were stained with an antibody against tau, which is known to exist almost exclusively in axons. Points of fluorescent signal were seen in the MAP2-negative and tau-positive nerve cell processes of these neurons. These two lines of evidence established that BDNF exists not only within the nerve cell body and dendrites of neurons, but also in the axon and its branches. Furthermore, the velocity of movement of these points representing BDNF could be measured and was approximately $0.3 \mu \mathrm{m}$ per second, comparable to the velocity of a synaptic vesicle protein that had been previously measured.

The important question was to ask if the BDNF in the axons can move transsynaptically to the target or post-synaptic neurons. To answer this question, Kohara et al. simultaneously injected two different plasmids into the nucleus; one plasmid containing the GFP-tagged BDNF and another one containing another dye referred to as DsRed. These two distinct protein products within a single neuron was detected by changing the wave length of the fluorescent excitation. DsRed and GFP-BDNF were expressed together within the nerve cell body and nerve cell processes of these plasmid-injected neurons. Again using an antibody to map tau, it was demonstrated that DsRed-positive material was within terminals of an axon that surrounded the nerve cell body of a post-

\section{Continued on page 34}

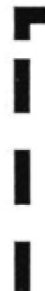

\section{INDEX OF ARTICLES}

Watching Neurons Hand Off Molecules Stephen W. Carmichael, Mayo Clinic

Digital Image Tips: Adjusting Brightness And Contrast 8 In Micrographs Using PhotoShop $\mathbb{E}$

Bradley R. Johnson, Pacific Northwest National Lab

Using the PMT in a Laser Scanning Confocal Microscope..... 12 As a Digital Light Meter to Measure Detection Photon Efficiency Jim Pawley, University of Wisconsin

Calibration Of Electron Microscopes: How To Do This,.......... 14 How Often, Pit-falls, and Problems

M\&M 2001 Experts' Session on Core Facility Management

Debbie Sherman (Session Organizer), Purdue University

An Alternative Mechanism for Generation of Spherical ..........21 Debris Particles on Bearing Raceway Spalls

Patrick Tibbits, Emerson Power Transmission

Scanning Impedance Microscopy: From Impedance .22

Spectra to Impedance Images

Sergei Kalinin \& Dawn Bonnell, Univ. of Pennsylvania

A Suggested Procedure for Sampling "Suspect White ............2 28

Powders" Where Law Enforcement Agencies Require a

"Credible Threat" Before Responding

Mike Dalbey, University of California
Service Contracts: Manufacturers Vs. Insurance Companies 30 Ken Converse, Quality Images

Comments on Quantifying the Results of Electron-Probe ......32

Analysis of a Gold-Tin Solder

John Twilley, Art Conservation Scientist

Does The World Need A Traceable Ruler? 34 Joseph D. Geller, Geller MicroAnalytical Laboratory

Printer Paper Summary .......................................................... 35

Paula Allan-Wojtas, Agricultureand Agri-Food Canada

Tips on Sectioning Polyethylene .............................................. 37

Charles A. Garber, Structure Probe, Inc.

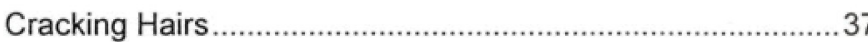

Steve Chapman, Pro-Train

A Comment on Adhesive Tabs Cracking in Sputter Coaters.. 37 Randy Tindall, University of Missouri

A Trick With Tripod Polishing .................................................37

Kim W. Pierson, University of Wisconsin

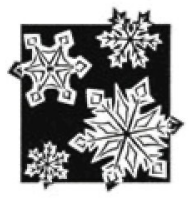


Watching Neurons Hand Off Molecules

Continued from page 4

synaptic neuron. The points of DsRed were demonstrated to be at pre-synaptic sites by co-localizing the DsRed signal with an immunocytochemical stain for a protein known to be associated with synaptic vesicles. referred to as synapsin I. Of particular interest, it was shown in the plasmid-injected neurons that GFP-BDNF and DsRed had virtually the identical distribution, whereas the nerve cell body of the post-synaptic neuron was only labeled with GFP-BDNF. These results suggest that BDNF was transferred from the pre-synaptic axon to the postsynaptic neuron because only the pre-synaptic neuron received the injection of plasmid, and the DsRed was not similarly transferred.

Next, Kohara et al. addressed the question whether the transfer of the GFP-BDNF was mediated through the BDNF receptor, referred to as TrkB. When the receptor was blocked with TrkB-immunoglobulin G, the GFP-BDNF was not transferred to the post-synaptic neurons. This suggested that TrkB mediates the transfer of BDNF. Finally, the relationship between neuronal activity and BDNF transsynaptic transfer was examined. When plasmid-injected neurons were paralyzed with tetrodotoxin, the nerve cell bodies of the neuron adjacent to the DsRed-positive terminals did not show any GFP signal. The results indicated that the transsynaptic transfer of BDNF was dependent on neuronal activity. This was further confirmed when picrotoxin, a molecule that excites neurons, was in the presence of plasmid-injected cells, the GFP signal almost doubled in the post-synaptic neurons, indicating that increased neuronal activity resulted in an increased transfer of BDNF.

Kohara et al. have used an elegant, although technically challenging technique to demonstrate the direct transsynaptic transfer of a neurotrophic factor. This almost certainly occurred in an anterograde direction. It is possible that axon terminals of the post-synaptic neuron may have contacted the nerve cell body of the plasmid-injected neuron and that BDNF might have been transported retrogradely to the nerve cell body of the post-synaptic neuron but this possibility appears to be unlikely because fluorescent signal was not detected in axons that came from post-synaptic neurons. These results indicate transneuronal transfer of BDNF is dependent on neuronal activity and is not part of a general movement of protein between neurons because the DsRed was not transported to post-synaptic neurons. The co-expression of two fluorescent proteins in the study made it possible for Kohara et al. to directly observe the activity-dependent, transneuronal transfer of BDNF. Quite an accomplishment!

1. The author gratefully acknowledges Professor Tadaharu Tsumoto for reviewing this article.

2. Kohara, K., A. Kitamura, M. Morishima, T. Tsumoto, Activity-dependent transfer of brain-derived neurotrophic factor to postsynaptic neurons, Science 291:2419-2423, 2001.

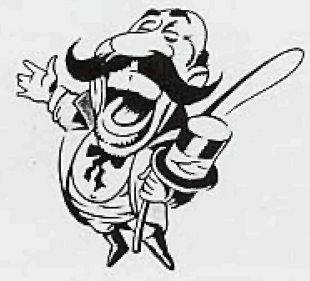

Does The World Need A Traceable Ruler?

Joseph D. Geller, Geller MicroAnalytical Laboratory jg@gellermicro.com

According to the International Standards Organization (ISO), for companies that are in compliance with ISO-9000 or QS-9000, traceable measurements shall be made when products or processes require dimensional measurements be made to a known uncertainty. These measurements are often made with a traceable ruler or micrometer. For magnification (the ratio of object size to image size) to be traceable, both the image and object size must be measured with calibration standards that have traceable dimensions. In the current ISO jargon the "uncertainty" of the instruments used to make the measurements must be known. The word "accuracy" is now only considered to be a subjective term and shall remain dimensionless. The uncertainty "budget" must consider all the factors, which may degrade the measurement result. This procedure is detailed in section 4.7 of the ISO-17025 (which replaced ISO Guide 25) "General Requirements for the Competence of Testing and Calibration Laboratories". This document is available from the International Standard Organization at www.iso.org.

In microscopy, the magnified image is usually measured with a ruler having millimeter graduations. To determine the magnification, the object that is magnified (calibration standard) shall also have dimensions with a known uncertainty. The resultant magnification is useful only under the specific conditions used. For details and procedures using the SEM see ASTM E766-98. For optical microscopy see ASTM E1951-98. These ASTM documents are available from www.astm.org.

So, do we really need a traceable ruler? How inaccurate can a ruler be? If we had the answer to that question we would not need one! During a trade show within the last several years I happened to visit a stand occupied by a national laboratory (many countries have national laboratories). They were giving away plastic rulers - both long and short ones. When I placed the $\mathrm{mm}$ markings on the long and short rulers together there was a discrepancy of about $0.5 \mathrm{~mm}$ over a length of $80 \mathrm{~mm}$. Which, if either, was accurate? All we know is that the measurements did not agree. If we had a traceable ruler the uncertainty of the "give aways" could be determined.

We have addressed this subject and developed a "traceable ruler". The MR-1 has a scale of $150 \mathrm{~mm}$ in length with minimum markings of $0.01 \mathrm{~mm}$. It is pretty "accurate". The uncertainty over the whole length of the scale is $+/-2.5 \mu \mathrm{m}$, and $+/-1 \mu \mathrm{m}$ over the first $10 \mathrm{~mm}$. Further information can be obtained at http://www.gellermicro.com/micro-ruler.pdf. Geller MicroAnalytical Laboratory is ISO-9001 certified and accredited to ISO-17025.

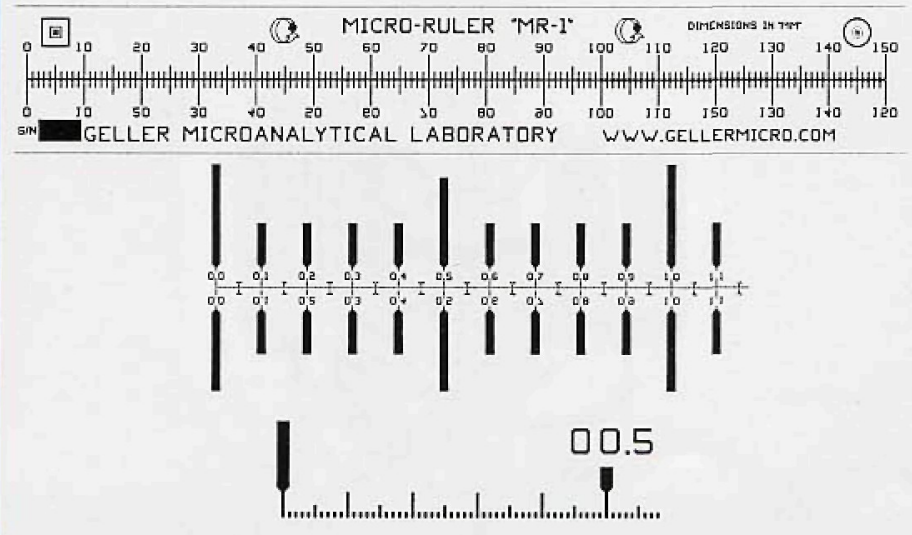




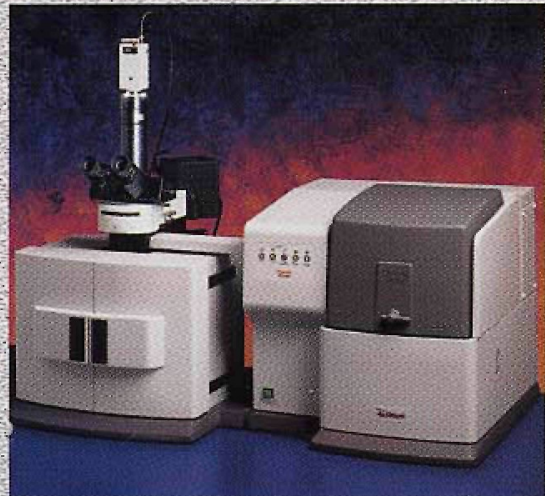

Almega ${ }^{\text {Th }}$ Disperstve Raman System

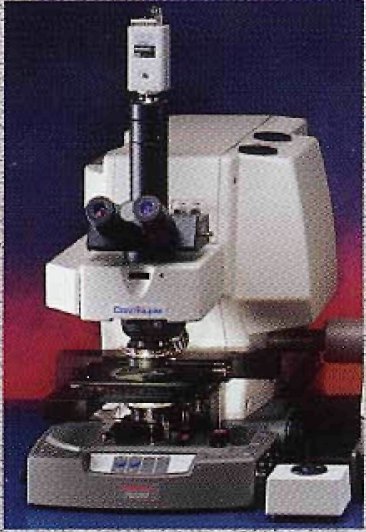

Continum m IR Mieroscope
Unmistakably family-with a personality all its own.

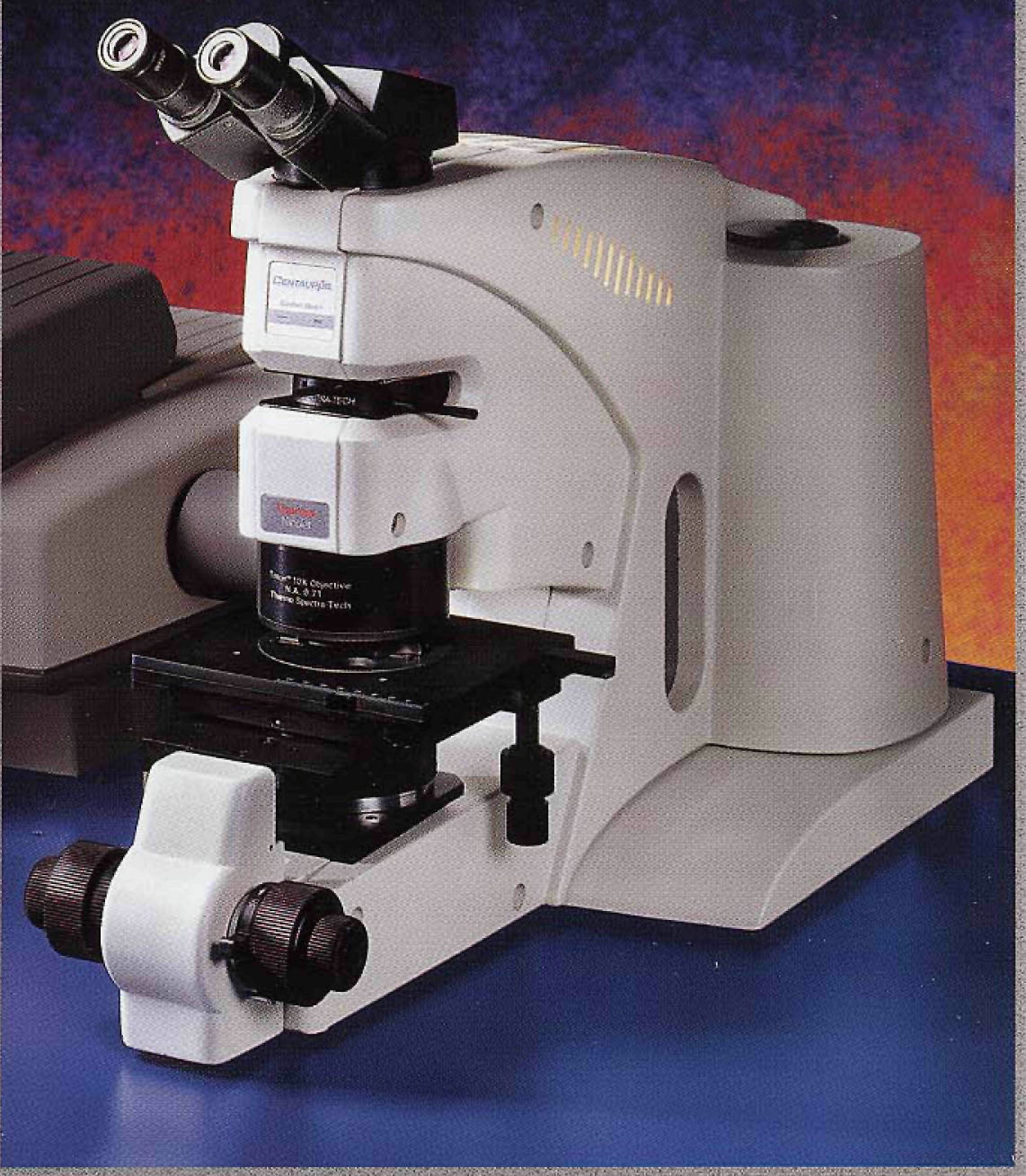

Meet our newest micro sampling family member, the Centaurus $5^{\text {Th }}$ IR microscope. At first glance, you'll notice it's compact and multitalented. A doser inspection will also reveal its rugged workhorse persona.

The talented micro sampling family from Thermo Nicolet embraces both IR and Raman technologies. With such an impressive lineup, you'll find one instrument with the exact capabilities to meet your needs.

To see which member of our micro sampling family best suits your situation, visit www.thermonicolet.com. Better yet, call us. Together we'll make a perfect match: 
- ANALYTICAL CHEMISTRY STARTER GRANT AWARD of $\$ 20,000$ to an assistant professor in the field of analytical chemistry by the Society for Analytical Chemists of Pittsburgh. The purpose of the grant is to encourage high-quality, innovative research by a new analytical chemistry professor and to promote the training and development of graduate students in this field.

For further information, contact Gerry Churley at $(800) 825$ 3221 Ext. 204 or by email: churley@pittcon.org

"Discover the Microscope" CD-ROM from Leica Microsystems-provides educators with the teaching tool they need to educate the next generation of scientists/students.

The interactive CD-ROM engages student interest through multi-media and throughly teaches the basics of how to use a microscope and the science of microscopy in general.

Topics include:

- Introduction to the microscope

- How to use a microscope

History of microscopy

Explanation of illumination techniques

- Exploration activities

- A working, virtual microscope

- A gallery of images

Leica offers a special introductory price of $\$ 89.00$ (plus $S \& H$ ) and may be ordered by calling Leica Customer Service at (800) 248-0123 Ext. 1.

\section{indGe CONEZOL inC.}

\section{"Your Image Is Our Concern"}

\author{
P.O. Box 1858
}

New Port Richey, FL 34656

Phone: 727 844-3744 or 703 369-0021

Fax: 703 257-6321

Web: www.imagecontrolinc.com

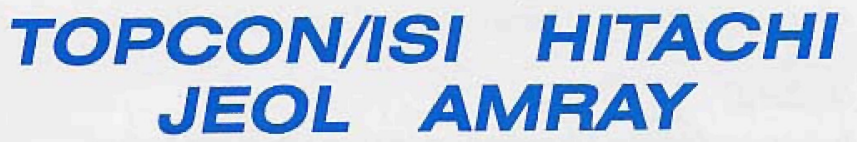

Service Contracts available at reasonable cost:

Unlimited Calls

Fixed Number of Calls Hourly Rates

- Servicing Electron Microscopes since 1966

- Engineers located strategically thru the U.S.

- Prompt and economical service

- Move units room to room or state to state

Quality prime used equipment for sale

\section{New Officers In 2002} Microscopy Society of America

President-Elect:

Alwyn Eades (Lehigh University)

Treasurer:

Kathleen Alexander ((Los Alamos National Laboratory)

Director-Biological Sciences:

Steven Samuelsson (P\&G Pharmaceuticals, Inc.

Director-Physical Sciences:

Nestor Zaluzec, Argonne National Laboratory

Microbeam Analysis Society

President-Elect:

Edgar Etz (National Institute of Standards \&Technology

Secretary:

Inga Holl Musselman (University of Texas-Dallas)

Directors:

Charlie Neilson (JEOL USA, Inc

Paul G. Kotula (Sandia National Laboratories)

- NIST-MAS Special Topics Workshop, postponed from 15/18 October 2001 is now scheduled for 8/11 April 2002. For attendance information contact Ryna Marinenko at (301)975-3901 or by email: ryna marinenkonist.gov

- 3D Microscopy of Living Cells, the 7th annual international 11 day short course, will be held on 10/20 June 2002 and its post-course workshop on 22/24 June 2002 at the University of British Columbia, Vancouver BC, Canada.

The course includes 4 days on $2 \mathrm{D}$ techniques, 5 days of 3D techniques and 2 days on 3D measurement and display. It includes everything from basic microscopy to confocal and multiphoton microscopy. A half day precourse is offerred for those wishing to brush up on basics.

Applications may be obtained from Prof. James Pawley: (608)263-3147, email: jpawley@facstaff.wisc.edu

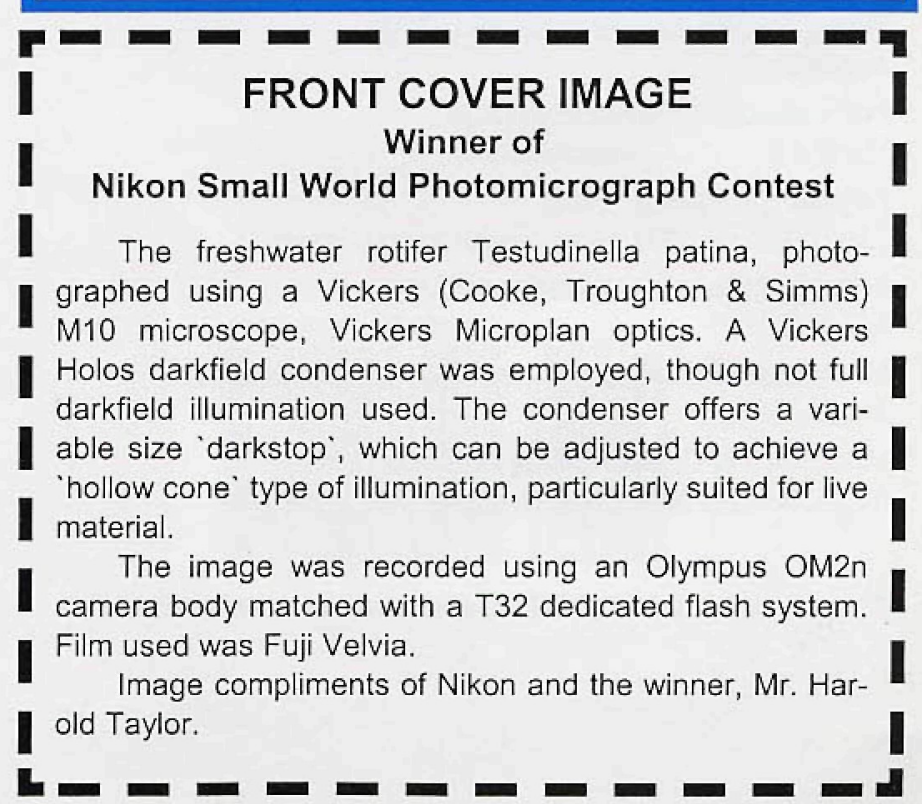




\section{MCCRONE RESEARCH INSTITUTE JANUARY - DECEMBER 2002 MICROSCOPY COURSES}

\section{Methods}

Applied Polarized Light Microscopy (1201)

$\begin{array}{lll}\text { January 21-25 } & \text { March 18-22 } & \text { April 29-May 3 } \\ \text { July 8-12 } & \text { August 26-30 } & \text { October 21-25 }\end{array}$

December 9-13

Advanced Applied Polarized Light Microscopy (1251*)

February 25-29 September 16-20

Chemical Microscopy (1202)

(Taught in Ithaca, NY at Cornell University)

January $14-18$

Digital and Video Microscopy (1105)

April 15-19 October 28-November 1

Fluorescence Microscopy (1210)

2-4 October

Microchemical Methods (1270A*)

October 14-18

Crystal Morphology and Optics (1301)

June 3-7

Particle Isolation, Manipulation and Mounting

for Additional Analysis (1501E)

November 4-8

Advanced Infrared Microspectroscopy (1422)

April 22-26 September 9-13

Microtome Methods for Light Microscopy (1502)

(Phone to register your interest)

Conoscopic Techniques for Polarized Light Microscopy (1310*)

(Next offered in 2003, phone to register your interest)

Scanning Electron Microscopy (1402)

April 8-12 November 11-15

\section{Specialities}

Scientific Imaging (1107)

November 18-22

Microscopy for Art Conservators (1206)

August 26-30

Pharmaceutical Microscopy (1203)

March 4-8 September 23-27

Polymer Microscopy (1205)

(Next offered in 2003, phone to register your interest)

Pollen and Spore Identification (1537)

July 8-12

Microscopy of Food and Foreign Body Identification (1560)

August 19-23

Microscopy of Crystal Caking Problems (1760)

(Next offered in 2003, phone to register your interest)

*Prerequisites: course 1201 (PLM) or consent of instructor; 1608A for $1608 \mathrm{~B}$

\section{Materials / Forensics}

Forensic Microscopy (1204)

(Same as 1201 Applied Polarized Light Microscopy)

Advanced Forensic Microscopy (Trace Evidence) (1701*)

(Same as 1251 Advanced Applied Polarized Light Microscopy)

February 25-29 September 16-20

Forensic Hair and Fiber Microscopy (1207)

May 20-24

Forensic Microscopy of Glass (1712)

May 13-17

Forensic Botanical Microscopy (1720)

September 16-20

Microscopy of Detrital Minerals (1503)

July 15-19

Wood and Vegetable Fiber Microscopy (1540)

June 10-15

Forensic Fiber Analysis: Advanced Microscopy

and Microchemistry (1507)

August 5-9

Comparative Microscopy of Soils (1710

Microscopy of Illicit Drugs and Excipients (1726*)

Forensic Paint Microscopy (1715)

(Next offered in 2003, phone to register your interest)

\section{Asbestos / Environmental}

Microscopical Identification of Asbestos (1608A)

February 4-8 April 8-12 June 3-7

August 12-16 September 30-Oct. 4 December 2-6

Advanced Asbestos Identification (1608B*)

November 11-15

Indoor Air Quality: Fungal Spore Identification (1630)

January 14-18 February 18-22 March 11-15

April 1-5 May 20-24 July 29-August 2

September 9-13 November 11-15 December 9-13

Indoor Air Quality: Advanced Fungal Spore Identification (1631) April 11-13

Advanced Indoor Air Quality: Fungal Culture Plate Identification (1632)

October 17-19

Indoor Air Quality: Identification of House Dust and Indoor

Particles (1633)

April 25-27

Asbestos Fiber Counting (NIOSH 582) (1616)

February 11-15 October 7-11

More information about microscopy courses, publications and I/M-2002 can be found on our Home Page on the World Wide Web at: http://mcri.org 


\section{Ooming atenth}

NEW YORK MICROSCOPICAL SOCIETY 2002 WORKSHOPS

$\checkmark$ April 20 \& 27, May 4 \& 11: Polarized Light Microscopy

$\checkmark$ May 3: Digital Image Capture \& Management in Light Microscopy Montclair, NJ, Donald O'Leary: (201)797-8849, donoleary@att.net

YEAR 2002 APPLIED OPTICAL MICROSCOPY CALENDAR Smithsonian Ctr for Materials Research \& Educ. (Suitland, MD)

$\checkmark$ March 11/15: Microscopy of Protective and Decorative Coatings

$\checkmark$ April 8/12: Practical Wood Anatomy in a Museum Environment

$\checkmark$ July 8/12: Polarized Light Microscopy-kFundamentals and Applications

For further information: Ms. Francine Lewis: (301)238-3700 X102

$\checkmark$ Feb 4/8 '02: ACEM 17th Australian Conference On Electron Microscopy Adelaide, www.adelaide.edu.au/CEMMSA/acem17/ main.htm

$\checkmark$ March 17/22 '02: PITTCON 2002 New Orleans, LA. (412)8253220, program@pittcon.org

$\checkmark$ April 8/10 '02: NIST-MAS Special Topics Workshop, Understanding the Accuracy Barrier in Quantitative Electron Probe Microanalysis and the Role of Standards. (NIST), Gaithersburg, MD. (301)417-1321, www.ni st.gov

$\checkmark$ May 5/8 02: Food Structure \& Functionality Symposium Montreal Quebec, www. aocs.org/member/division/fsff/index.htm

$\checkmark$ May 9/17 '02: Analytical \& Quantitative Light Microscopy

$\checkmark$ May 21/28 '02: Microinjection Techniques in Cell Biology (Marine Biological Lab) Woods Hole, MA, Carol Hamel, (508)2897401, admissions@mbl.edu $\checkmark$ May 22/June 1: EMBO Practical Course on Electron Microscopy, Immunocytochemistry and Stereology for Cell Biology (EMBL) Heidelberg, Germany. www.db.embl-heidelberg.de/CoursesConferecnes. html

$\checkmark$ June 5/12 '02: Optical Microscopy in the Biological Sciences (Univ. of Texas Health Science Ctr), San Antonio, TX, Victoria Centonze Frohlich, frohlich@uthscsa,edu,

www.uthscsa.edu/csb/image/Announcements.html

$\checkmark$ June 10/20: 3D Microscopy of Living Cells (\& June 22/24: Postcourse Workshop) Vancouver, BC, Canada. www.3dcourse.ubc.ca/home. html

2002 LEHIGH MICROSCOPY SCHOOL

$\checkmark$ June 10/14: SEM and X-ray Microanalysis

$\checkmark$ June 9: Introduction to SEM and EDS

$\checkmark$ June 17/20: Advanced Scanning Electron Microscopy

$\checkmark$ June 17/20: Quantitative X-ray Microanalysis

$\checkmark$ June 17/20: Analytical Transmission Electron Microscopy

$\checkmark$ June 18/21: EM Specimen Preparation

$\checkmark$ June 18/21: Atomic Force Microscopy

$\checkmark$ June 17/20: Characterization of Nanostructures Lehigh Universtiy, Bethlehem, PA

For info: Sharon Coe, (610)758-5133, sharon.coe@lehigh.edu

$\checkmark$ June 24/27 '02: 17th Annual Short Course on Molecular Microspectroscopy (Miami Univ.) Oxford, $\mathrm{OH}$ (513)529-2874, Www. muohio.edu/mml

$\checkmark$ July 9/11 '02: MICROSCIENCE London, UK, Info@rms.org.uk, www.rms.org.uk/microscience2002

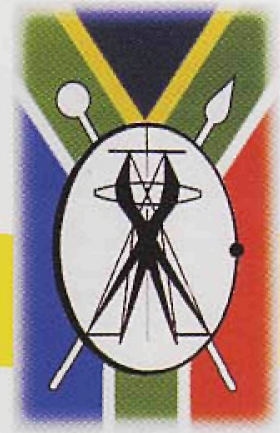

The Microscopy society of Southern Africa

is proud to invite you to

\section{World focus on microscopy}

\section{1- 6 september 2002}

The $15^{\text {th }}$ International Congress on Electron Microscopy (ICEM 15) will be held at the International convention centre in Durban, south Africa from the $1^{\text {st }}$ to the $\sigma^{\text {th }}$ of september 2002.

We invite you to attend the platform, poster, invited speaker presentations and trade exhibitions on the latest in microscopy and all its fascinating applications.
Long golden beaches and the warmth of the Indian Ocean is what makes Durban South Africa's most popular domestic tourist destination. Situated in Kwazulu Natal it is only a short drive from the spectacular Drakensberg Mountain resorts and the excitement of African wildlife sanctuaries.

Accommodation is readily available and range from beachfront Holiday Inns to the Hilton, and most are in close proximity to the conference venue.

The facilities include a 3000 seat auditorium for opening ceremonies, spacious lecture halls and $3000 \mathrm{~m}^{2}$ indoor exhibition area.

For all the details and online registration http:// www.icem15.com

For information on the Conference Venue http://www.icc.co.za

Conference organizers: Turners Conferences P. O. Box 1935, Durban, 4000, South Africa

Tel: +27313321451 Fax: +27313686623 e-mail: turner13@galileosa.co.za 